\title{
SPINAL INTRAMEDULLARY CYSTICERCOSIS
}

\author{
Lt Col PK SAHOO *
}

MJAFI 2000, $56: 240-241$

KEYWORDS:Cysticercosis; Intramedullary parasitosis

\section{Introduction}

Cysticercosis of the CNS is common in the cranial cavity. Spinal cysticercosis is an uncommon entity. Spinal intramedullary cysticercosis is quite rare compared to spinal subarachnoid cysticercosis. A young patient who presented with features of cervical myelopathy is reported. Magnetic resonance imaging (MRI) revealed intramedullary 'ring lesion'. Histopathology was suggestive of cysticercosis.

\section{Case report}

A 30-year-old lady presented with history of neckpain, left brachialgia and numbness left thumb and index finger of 6 months duration. Neurological evaluation revealed normal higher mental and cranial nerve function. Left grip was weak. Hypothesesia $C_{6}$ and $C_{7}$ dermatome on left side. Deep tendon reflexes were normal. Examination of cervical spine was normal. Radiography of cervical spine was normal. MRI cervical spine with gadolinium enhancement on sagittal and axial images revealed an intramedullary lesion at $C_{5}$ with central low signal intensity and peripheral high signal intensity occupying almost half of spinal cord (Fig-1 and 2). $\mathrm{C}_{4}$ and $\mathrm{C}_{5}$ laminectomy and microsurgical excision of a cystic lesion containing milky white fluid was done. Histopathology was suggestive of parasitic cystic lesion. Post-operatively albendazole $400 \mathrm{mg}$ bd for four weeks was given. She had an uneventful post operative period with improvement of pre-op neurological deficit.

\section{Discussion}

Spinal cysticercosis contrary to the cranial cysticercosis is an uncommon entity [1]. The reported incidence is less than $5 \%$ of the cranial counterpart [2]. Spinal intramedullary cysticercosis is quite rare and is 6 to 8 times less frequent as compared to spinal subarachnoid cysticercosis [3]. The clinical features of cysticercosis are related to both mass effect and toxic side effects due to release of parasitic metabolic byproduct. The cyst may expand within the cord and produce symptoms similar to those of a small syrinx. Hydromyelic cavities may occur as a consequence of intramedullary cysticercal cysts, resulting in deficits over a larger area. Cord compression may result from subarachnoid cysticercal cysts, which are generally more common than intramedullary cysts [4]. Vascular compromise secondarily results in cord ischaemia and myelomalacia. Toxic side effects include local inflammation secondary to leakage of parasitic metabolic byproducts within the cyst fluid. This too may result in ischaemia and myelomalacia.

Spinal cysticercosis may be easier to diagnose on MR imaging, presenting as a well defined, sometimes multiloculated intramedullary cyst that has signal characteristics similar to that of CSF. Contrary to common belief, the disease is not restricted to the pork

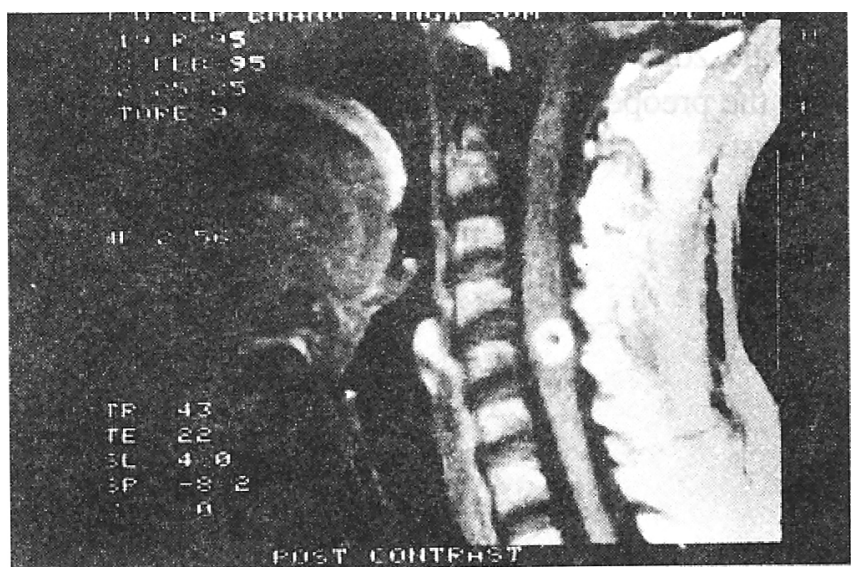

Fig. 1: MRI cervical spine sagittal view with gadolinium enhancement showing intramedullary ring lesion

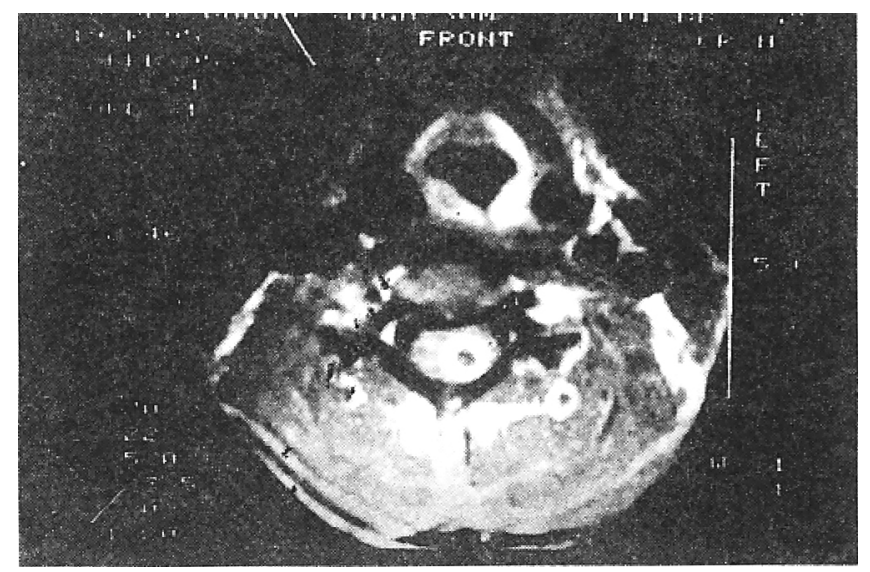

Fig. 2: MRI cervical spine axial view with gadolinium enhancement showing intramedullary ring lesion at $\mathrm{C}_{5}$ occupying more than half of spinal cord.

Classified Specialist (Surgery and Neuro Surgery), Command Hospital (AF), Bangalore, Karnataka-560 007. 
eater, who usually harbour the adult parasite. Most commonly cysticercosis occurs due to either ingestion of contaminated vegetables, eaten raw or autoinfection from faeco-oral route or by reverse peristalsis. It enters the circulation through the gastric mucosa and dissemination to the brain is the rule [5]. Although primary infestation of the spinal canal has been described in the literature, primary infestation of the cord rarely has been described. Proposed mechanism of spread to the spinal cord include haematogenous dissemination [4]. As haematogenous dissemination is proportional to the blood flow to the spinal cord, the thoracic cord which receives the greatest blood supply, is the most often affected (64\%) [6]. Spine can also be involved through the ventriculo ependymal spread by migration of larva from ventricle along the CSF down to the spinal subarachnoid space [7]. Surgery is the treatment of choice for symptomatic intramedullary cysticercosis. The present case showed excellent neurological recovery following surgery.

\section{REFERENCES}

1. Brown WJ, Voge M. Neuropathology of parasitic infection. Oxford: Oxford Medical Publication. 1992:108-37.

2. Taveras JM, Wood EH. Diagnostic neuro radiology. 2nd ed, Baltimore. The Williams and Wilkins company 1977:1162.

3. Kochan-JP, Quencer RM. Imaging of cystic and cavitary lesions of the spinal cord and canal. In: Modic MT, ed. The radiologic clinics of North America. Philadelphia, WB Saunders 1991; 29:867-911.

4. Castillo M, Quencer RM, Post MJD. MR of intramedullary spinal cysticercosis. Am J Neuro Rad 1998;9:393-5.

5. Carey ME. Infection of the spine and the spinal cord. In: Youman JR, ed. Neurological Surg, 3rd ed. Philadelphia, WB Saunders 1990;3759-81.

6. Sousa LW, Filho AP, Callegaro D. Intramedullary cysticercosis, case report, literature review and comments on pathogenesis. J Neurological Sciences 1975;26:61-70.

7. Kramer J, Carrazana E, Cosgrove GR, Leefield J, Edelman RR. Transaqueductal migration of Neurocysticercus. J Neurosurg 1992;77:956-8. 